\title{
FREUD, ¿PEDAGOGO O ANTIPEDAGOGO?
} UNA CONVERSACIÓN POSIBLE CON LOS TEXTOS DE MILLOT Y CIFALI

\section{IS FREUD PEDAGOGICAL OR ANTIPEDAGOGICAL? A POSSIBLE DIALOGUE WITH MILLOT AND CIFALI'S TEXTS}

Fecha de recepción: 04/4/19 Fecha de aceptación: 14/4/19

\section{VERÓNICA ESCUDERO}

Lic en Psicología Universidad Nacional de La Plata (UNLP)Asociada a la Escuela de la Orientación Lacaniana EOL-Sección La Plata. Integrante del Departamento de Estudios sobre el Cuerpo (DEC) de la Escuela de Orientación Lacaniana (EOL). Co-Responsable de los semanarios "Los campos del Goce" (2017) y "Los campos del goce: lecturas de la tercera" (2018) en EOLSección La Plata.
Resumen: A partir de la afirmación freudiana que dice que educar, psicoanalizar y gobernar son profesiones imposibles, este trabajo recorre los aportes de dos libros, Freud antipedagogo de Catherine Millot (1990) y ¿Freud pedagogo? de Mireille Cifali (2003), con el propósito de examinar los desarrollos freudianos sobre las relaciones entre psicoanálisis y pedagogía. Planteado como una conversación entre textos se tratará de situar la enunciación propia de cada autora.

Palabras claves: Psicoanálisis - Pedagogía - Millot- Cifali

Si tenemos que pensar la relación de Freud con la pedagogía seguramente partiríamos de que educar, psicoanalizar y gobernar son profesiones imposibles. También podríamos reconocer que es una afirmación tardía dentro de la extensión de su obra, que data de 1937 en "Análisis terminable e interminable". Texto que ha trascendido en el campo del psicoanálisis por señalar "la roca viva de la castración" como el "imposible freudiano”, ¿pero respecto de qué se señala lo imposible de estas profesiones? Para Catherine Millot, las tres prácticas descansan sobre los poderes que un hombre puede ejercer sobre otro merced a la palabra, y las tres encuentran su límite de acción en que algo se resiste a la palabra; mientras que
Abstrac: On the basis of Freudian statement that educating, psychoanalyzing and governing are impossible professions, Freud antipedagogo by Catherine Millot andiFreud pedagogo? by Mireille Cifali are traced back to explore Freudian ideas in this field. The dialogue between these two texts does not involve making them answer each other or making their temporal appearance reveal an absolute truth.

Key words: Psychoanalysis -Pedagog - Millot - Cifali

del texto de Mireille Cifali se deprende que tienen una ética en común: la irreductibilidad del sujeto. Me voy a servir del recorrido de dos textos: Freud antipedagogo 1 de Catherine Millot, $\mathrm{y}_{\text {¿Freud }}$ pedagogo? 2 de Mireille Cifali para explorar el pensamiento freudiano sobre el tema. Hacer conversar los textos no implica que uno conteste al otro, ni que la aparición temporal de los mismos, otorgue una verdad última. Plantear así la cosa haría perder la enunciación propia de cada una de las autoras, y el trabajo exhaustivo de reflexión sobre la obra freudiana en sí misma y en relación a la educación.

Millot afirma de entrada que "No encontramos en la obra de Freud ningún tratado de educación 
[...] ¿Se trata de negligencia o de una falta de interés personal?" 3, esgrimiendo de entrada su hipótesis: la carencia de prescripciones pedagógicas en Freud tiene causas ligadas a los propios descubrimientos del psicoanálisis. Desde allí hace su lectura. Mientras que Cifali ubica el problema en torno a la "aplicación" del psicoanálisis y la pedagogía, desentramando desde esa perspectiva el pensamiento freudiano y la política que lo concierne al mismo Freud respecto del porvenir de su "hijo", el psicoanálisis.

Cada una con su perspectiva y sus diferencias permiten abordar dos temas que, en mi lectura, toman relieve: la civilización y la infancia.

\section{CIVILIZACIÓN Y POLÍTICA}

Para Millot el problema de la educación en Freud se inscribe en otro más general, el de las relaciones del individuo con la civilización. Y será, entonces, a partir de cómo Freud fue pensando la misma que se irá precisando y delineando la posición freudiana respecto de la educación. Para Cifali, en cambio, el interés originario sobre la aplicación del psicoanálisis a la pedagogía, radica en el deseo freudiano de arrancar el psicoanálisis del campo médico, por temor a que quede reabsorbido y neutralizado en ese campo. Ella lee una intención política de Freud en sus textos "sociales" que tiene que ver con su preocupación por el porvenir del psicoanálisis. Las dos señalan el interés de Freud en pensar la "época" desde el psicoanálisis, y se ubica en ese campo la relación del mismo con la pedagogía.

El análisis minucioso de Millot sobre el devenir del estudio de la causa de la neurosis en los desarrollos freudianos es la columna vertebral para seguir los principios de la práctica misma del psicoanálisis, así como para señalar el lugar asignado a la educación en el de la relación entre civilización y sexualidad. Lo que podríamos sintetizar en un arco que va desde la función preventiva de la educación en la causa de la neurosis, hasta el pesimismo de definirla como "profesión imposible". Los puntos nodales en este arco serían: el descubrimiento de la sexualidad infantil, la teorización de las pulsiones yoicas y sexuales, y por último la paradoja del más allá del principio del placer y su malestar en la cultura. Con esto intento cernir los virajes que ilumina la autora sobre la concepción freudiana de neurosis, y como correlato las funciones que asigna, de manera más o menos explícita, a la educación. Quiero resaltar aquí su trabajo de lectura, ya que como ella misma nos dice: no hay ningún tratado. Cifali señala lo mismo: "a veces (Freud) dio algunos consejos, esbozó a grandes rasgos los fines de una pedagogía de acuerdo con un punto de vista analítica, pero eso es más o menos todo".4

De ubicar la causa de la neurosis en la moral represiva de la época, donde la ilusión de una reforma pedagógica contribuiría a "prevenirla", a plantear en la propia sexualidad humana, signada por dos tiempos, el factor filogenético de la causa de neurosis vemos palidecer la aspiración reformista de Freud sobre la educación. El descubrimiento de la sexualidad infantil instala desde otra perspectiva la relación del individuo con la civilización a partir del análisis de las pulsiones parciales. El "perverso polimorfo" abrió camino a pensar la sublimación como satisfacción pulsional más allá del fin sexual y de la hegemonía genital post latencia. Es particularmente interesante la lectura que hace de ello Millot, al señalar que el descubrimiento de la sublimación al servicio de fines culturales ya no permite plantear una oposición radical entre sexualidad y civilización, por lo tanto, se pregunta qué función podrá tener la educación en este paradigma, y dice. "Al igual que el pedagogo tradicional, Freud reconoce la existencia del "mal" en el niño. Pero lejos de que deba procurarse la extirpación de las "malas inclinaciones" del niño- de todos modos, indestructibles- hay que dejarlas derivar hacia una salida socialmente aceptable. No hay sublimación sin perversión" 5 . Lectura precisa del texto freudiano "Múltiple interés del psicoanálisis" de 1913, que revela la vigencia de este señalamiento en la actualidad: la orientación coercitiva externa no garantiza el apaciguamiento de lo pulsional. Y desde esta perspectiva es que Freud plantea la tarea del educador como hallar el justo equilibrio entre el Caribdis del dejar hacer y el Escila de la prohibición. Millot avanza hacia lo irreductible de la pulsión de muerte freudiana y el malestar en la civilización, producto de la relación del sujeto con lo simbólico que produce una desgarradura del ser humano con el mundo y consigo mismo. Sobre este punto afianza su afirmación más concluyente: la de la oposición radical entre el proceso analítico y el proceso pedagógico, agregando que "la incidencia del psicoanálisis en la civilización moderna no pasa en modo alguno por una reforma educativa" 6 . Sin embargo, abre la posibilidad que de 
la experiencia analítica pueda deducirse una ética en la que la pedagogía pueda inspirarse.

A la luz de lo que Millot plantea como oposición radical entre psicoanálisis y pedagogía, resulta interesante tomar la vertiente que propone Cifali en torno al planteo de la "aplicación". Freud no hizo una doctrina de la aplicación, más bien, dice la autora, mostró en acto en casos particulares como aplicar el psicoanálisis. Y recorre en ese punto los riesgos de la aplicación: desde tomar una política colonizadora y convertir al psicoanálisis en una "teoría madre", hasta posibles desvíos que nos lleven fuera del psicoanálisis. Ella empuja su elaboración a ese punto de una posible aplicación en la que se produzca, a partir del encuentro entre las disciplinas, la emergencia de un saber nuevo. $\mathrm{Ni}$ colonia, ni colonizador. Es muy interesante el recurso al análisis de la correspondencia de Freud, sobre todo con Pfister, pedagogo suizo. Sabemos del valor que tiene en la obra freudiana el análisis de sus "cartas", pero lo que quisiera señalar del trabajo de esta autora es que parece buscar allí lo que Freud dice entre líneas, más allá de sus enunciados. Desentramando un punto, que también me parece de mucha actualidad, que es el de la supervivencia del psicoanálisis en la civilización. De este modo enmarca los dichos de Freud, respecto de la educación entre otras disciplinas, dentro del interés por la "empresa freudiana", la de convertir al psicoanálisis en una "herramienta" que eche luz a las ciencias del hombre. Esto lo interpreta con una doble finalidad encender la "chispa" en el campo del Otro, para después servirse de su "tizón", parafraseando palabras de Freud.

\section{INFANCIA Y SABER}

La infancia es el telón de fondo de las reflexiones sobre el psicoanálisis y la pedagogía, planteada en términos de mayor maleabilidad psíquica en el texto de Millot, o como reservorio narcisista para los padres, donde se proyecta la ilusión del provenir de las generaciones futuras, tal como lo plantea Cifali. Millot ilumina un punto que vale la pena destacar: el fracaso de enseñar a los niños sobre sexualidad, ya que ha quedado demostrado que ellos mantienen sus "teorías"más allá de la enseñanza del adulto. Interesante perspectiva para repensar qué es lo "enseñable".

Lo cierto es que no hay infancia sin institución, ya sea la familiar o la que eventualmente la sustituye, la educativa, la escolar, lo que nos invita a pensar la "necesidad" de su existencia. ¿Es posible una infancia o una civilización sin instituciones? Traigo aquí lo que Lacan denominó "lo irreductible de una transmisión", como lo que se transmitemás allá de la tradición y se encarna en un deseo que no es anónimo. Despertar el deseo de saber en un niño es una apuesta que compartimos psicoanalistas y educadores. El punto de reflexión es qué entendemos por saber en cada caso, y desde donde se opera porque si bien el analista pone de su parte "no es un poner activo como el de la pedagogía (...) no se trata de forzar desde un saber que entraña un dominio sobre el goce..."7

Lacan usó la expresión alfabestializar para hacer referencia a la intrusión reguladora sobre el goce singular de cada uno. Pero, ¿la educación podría tener otra función? El recorrido de estas perspectivas amplía el horizonte para pensar la función del psicoanálisis en el reverso de la política pedagógica, haciendo posible una escritura singular para lo ineducable. Pero también abre el terreno de pensar una interlocución posible con el discurso de la pedagogía, del cual Freud señaló que también lo habita un imposible.

Notas

1. Millot, C.: Freud antipedagogo, Editorial Paidós, México, 1990.

2. Cifali, M.: ¿Freud pedagogo? Siglo XXI, Buenos Aires, 2003.

3. Millot, C.: "Introducción", op.cit (1), p. 9.

4. Cifali, M.: "Educación una aplicación que no es como las otras", ¿Freud pedagogo? Siglo XXI, Buenos Aires, 2003, p. 41

5. Millot, C.: "Sexualidad y civilización" op.cit (1), p. 34.

6. Millot, C.: "Psicoanálisis y educación" op.cit (1), p. 157.

7. Leserre, A.:Una lectura de Nota sobre el niño, Grama Ediciones, Buenos Aires, 2015, p.23.

\section{Bibliografía}

- Freud, S.: "El malestar en la cultura", en Obras completas Libro XXI, Amorrortu, Argentina, 1989.

- Freud, S.: "Análisis terminable e interminable", en Obras completas Libro XXIII, Argentina, 1989

- Lacan, J.: “Dos notas sobre el niño", en Otros escritos, Paidós, Buenos Aires, 2012

- Lacan, J.: Seminario XXI “Les non-DupesErrent”, inédito. 